Article

\title{
Mining Sequential Patterns of Diseases Contracted and Medications Prescribed before the Development of Stevens-Johnson Syndrome in Taiwan
}

\author{
Chao Ou-Yang ${ }^{1}$, Shih-Chung Chou ${ }^{1}$, Yeh-Chun Juan ${ }^{2,3}$ and Han-Cheng Wang ${ }^{4,5,6, *}$ \\ 1 Department of Industrial Management, National Taiwan University of Science and Technology (Taiwan \\ Tech), Taipei 10607, Taiwan; ouyang@mail.ntust.edu.tw (C.O.-Y.); D10401002@mail.ntust.edu.tw (S.-C.C.) \\ 2 Department of Industrial Engineering and Management, Ming Chi University of Technology, \\ New Taipei City 24301, Taiwan; ycjuan@mail.mcut.edu.tw \\ 3 Department of Industrial and Business Management, Chang Gung University, Taoyuan 33302, Taiwan \\ 4 Department of Neurology, Shin Kong Wu Ho-Su Memorial Hospital, Taipei 11101, Taiwan \\ 5 College of Medicine, National Taiwan University, Taipei 10051, Taiwan \\ 6 College of Medicine, Taipei Medical University, Taipei 11031, Taiwan \\ * Correspondence: M000737@ms.skh.org.tw
}

Received: 20 May 2019; Accepted: 12 June 2019; Published: 14 June 2019

\begin{abstract}
Medication is designed to cure diseases, but serious risks can arise from severe adverse drug reactions (ADRs). ADRs can lead to emergency room visits and hospitalization, straining healthcare resources and, thus, they have strong implications for public health. Stevens-Johnson Syndrome (SJS) is one ADR and comprises the highest proportion of all drug relief cases in Taiwan. Pharmacovigilance involves the collection, detection, assessment, monitoring, and prevention of ADRs, including SJS. Most medical specialists are not fully aware of the risk of drug-induced SJS. Consequently, various drugs may be prescribed to susceptible patients for a great variety of diseases and, in turn, cause SJS. In this research, medical records of SJS patients were retrieved from the Taiwan National Health Insurance Research Database, and the Generalized Sequential Patterns (GSP) algorithm was used to find the sequential patterns of diseases before SJS onset. Then we mined the sequential patterns of medications prescribed in each disease pattern. Afterwards, we detected significant associations of each pattern of diseases and medications prescribed among age groups with statistical analysis. We found that, first, most patients developed SJS after being prescribed the causative medications fewer than four times. Second, Respiratory System Diseases (RSDs) appeared in disease sequential patterns of all lengths. Patterns involving RSDs were more frequent than others. Third, NSAIDs, H2-antagonists for peptic ulcer, penicillin antibiotics, theophylline bronchodilators, and cephalosporin antibiotics were the most frequent medications prescribed. Fourth, we found that patients in certain age groups had higher risks of developing SJS. This study aimed to mine the sequential patterns of diseases contracted and medications prescribed before patients developed SJS in Taiwan. This useful information can be provided to physicians so that they can stop the administration of suspected drugs to avoid evolution towards more severe cases.
\end{abstract}

Keywords: Stevens-Johnson Syndrome; sequential pattern mining; adverse drug reactions; healthcare; data mining

\section{Introduction}

The public spends billions of dollars on prescription drugs which are designed to cure, treat, or prevent diseases. However, when taking any medication, some risks should be taken seriously. Severe adverse drug reactions (ADRs) can lead to patient morbidity [1]. In the U.S., ADRs have been 
estimated to send 701,547 patients to emergency rooms, hospitalize 117,318 patients each year [2], account for $2-6 \%$ of all hospital admissions, and increase the duration of hospital stays and costs [3]. Moreover, over 2 million serious side effects, including 100,000 deaths, occur due to ADRs [4]. In other words, ADRs strain healthcare resources and thus have strong implications for public health [5].

Pharmacovigilance involves the detection, assessment, understanding, and prevention of ADRs [1] that were previously either unknown or poorly understood. Despite progress in pharmacovigilance, the burden on public health of ADRs remains significant [6]. In recent years, data mining of electronic health records (EHRs) has emerged as a promising complementary method for drug safety surveillance [5]. Data mining in pharmacovigilance has attracted significant attention and has the potential to discover complex interactions that defy human recognition [7].

ADRs also occur in Taiwan. In 2017, 15,422 cases of ADRs were reported [8]. According to the statistics of the Taiwan Drug Relief Foundation, from 1999-2017, 1685 drug relief cases were approved in Taiwan, and the relief amount was NT $\$ 454,192,519$. Of these cases, $610(36.2 \%)$ cases were related to Stevens-Johnson Syndrome (SJS); it was the highest proportion of all drug relief cases [9]. SJS is a severe disease mainly caused by ADRs. To reduce the mortality rate due to SJS, healthcare workers must share the responsibility for safe drug use.

SJS was first described in 1922 by two American physicians named Stevens and Johnson [10]. It is a rare (2-6 cases/million/population/year) disease [11] characterized by widespread epidermal necrosis involving the skin and mucous membranes [12-16]. SJS is among the most notorious severe cutaneous adverse reactions (SCARS) due to its rapid progression and high mortality rate. The reported mortality rate of SJS is $1-5 \%$ [16]. It is an emergency medical condition that usually requires hospitalization $[17,18]$. Due to the importance of SJS, thousands of studies have focused on it since 1940 [19].

Studies have indicated that SJS occurs more frequently in women than in men [13,20]. Although some studies have found that the ages of patients with SJS are age-stratified [19,21-23], the patients affected by SJS range from infants to the elderly [23]. One study found that SJS occurred predominantly in children and adolescents [22], yet another study found that many SJS patients were elderly persons with underlying medical conditions that required regular medical treatment [11]. In summary, most of the studies to date have indicated that children and the elderly are more susceptible to SJS.

Although the pathogenesis of SJS is not fully understood [16,21,24-26], most studies have found that it is predominantly medication-induced [11-13,16,19,21,24-28]. The proportion of SJS cases attributable to medications is estimated to be greater than 50\% [13]. During the treatment of patients with SJS, the first and most important step is to identify and discontinue any possible responsible medications [24].

Although more than 100 medications have been implicated as causes of SJS [12,13,29], certain medications have higher probabilities of causing SJS than others. The most common medications associated with SJS are antibacterial sulfonamides, anticonvulsant agents, oxicam NSAIDs, allopurinol, chlormezanone, and corticosteroids [12]. Other medications also induce SJS but to a lesser degree, two examples being theophylline [30,31] and H2-antagonist [32,33].

Most (85-100\%) of the medications "highly suspected" of triggering SJS are initiated in treatment less than 8 weeks before that complication. In general, no significant risk persists after eight weeks of use [34], indicating that the highest risk of inducing SJS occurs during the initial two months. Therefore, a study of drug records within the two months prior to SJS would be most relevant.

SJS is predominantly medication-induced [11-13,16,19,21,24-28]. However, physicians generally lack sufficient information on the risk of causing SJS when they prescribe medications for a broad range of diseases.

Few studies have examined the relationship between diseases contracted and medications prescribed before patients developed SJS, but they have led to interesting discoveries. One study identified the most commonly-implicated medications responsible for SJS in HIV/AIDS patients [24]. Other specific disease groups, such as cancer, tuberculosis, hypertension, and diabetes mellitus, have all been studied in research on SJS [19]. 
Moreover, some studies have indicated that many Taiwanese, who are Han Chinese, have a gene called HLA-B 1502, which increases the risk of SJS induced by medications [35,36]. Therefore, the incidence rate in Taiwan is about eight cases/million/population/year [37]. In short, Taiwanese are at a higher risk of SJS than other populations are.

In summary, despite this great concern about SJS, the relationship between the sequence of suspected medications and diseases contracted prior to SJS has never been examined. Therefore, this study aimed to mine the sequential patterns of diseases contracted and medications prescribed before patients developed SJS in Taiwan. This information could be quite useful. On one hand, this helpful information can be provided to physicians who are not really familiar with SJS so that they can avoid prescribing suspected drugs to SJS patients. On the other hand, it can also be provided to SJS patients and those who are at high risk of getting SJS so that they can pay attention to their prescriptions from different specialized physicians.

\section{Methods}

Taiwan has a single-payer National Health Insurance program. As of 2014, 99.9\% of Taiwan's population was enrolled in this program. This study is based on information from the Taiwan National Health Insurance Research Database (NHIRD).

To find the sequential patterns of diseases contracted and medications prescribed before the development of SJS, this study proposed the research framework presented in Figure 1.

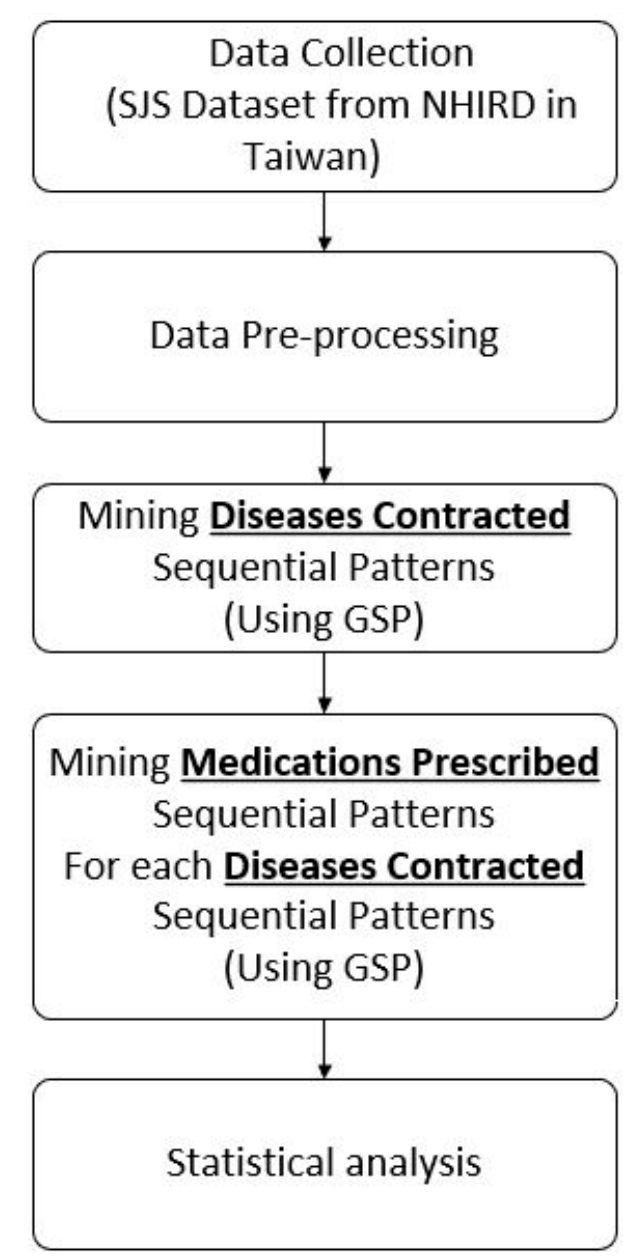

Figure 1. Research framework.

First, we retrieved from the NHIRD the treatment records of SJS patients in Taiwan from one year (2008). These records included the details of inpatient visits, ambulatory care, and drug prescriptions. 
Second, we pre-processed the treatment and medical records before the patients developed SJS by time series. Third, to identify the most likely disease patterns, we developed the sequential patterns of the diseases with the Generalized Sequential Patterns algorithm (GSP) [38] and retrieved patients' treatment records. Fourth, we used GSP to identify the sequential patterns of prescribed medications for each disease sequential pattern. Finally, after statistical analyses among the age groups, we developed useful conclusions based on the two sequential patterns mentioned above.

Next, this study continued mining the drug patterns based on the above-mentioned disease patterns. We expected the study of these two sequential patterns to provide physicians with useful information on medication safety.

\subsection{Data Collection}

This research used the NHIRD database, which plays an important role in healthcare in Taiwan. It is a large computerized database managed by the National Health Insurance Administration (the former Bureau of National Health Insurance, BNHI). Each year, the BNHI collects data from the National Health Insurance program, including registration files and original claim data for reimbursements, and stores them in data files. These data files are de-identified by scrambling the identification codes of both patients and medical facilities and shipped to the National Health Research Institutes to form the original files of the NHIRD.

The database includes information on patients' diagnoses and medications prescribed. For this work, the records of diagnosis and prescription data of SJS patients (ICD-9-CM, code: 695.1) [39] for one year (2008) were retrieved from the NHIRD.

As Figure 2 shows, the database has four subsets. One subset of the database provides information on inpatient visits and inpatient expenditures by admission (DD), and two subsets of the database contain the information on outpatient visits, known as ambulatory care expenditures by visit (CD) and the details of ambulatory care orders (OO). The last subset of the registration databases provides the information on medications (Drugs) [40].

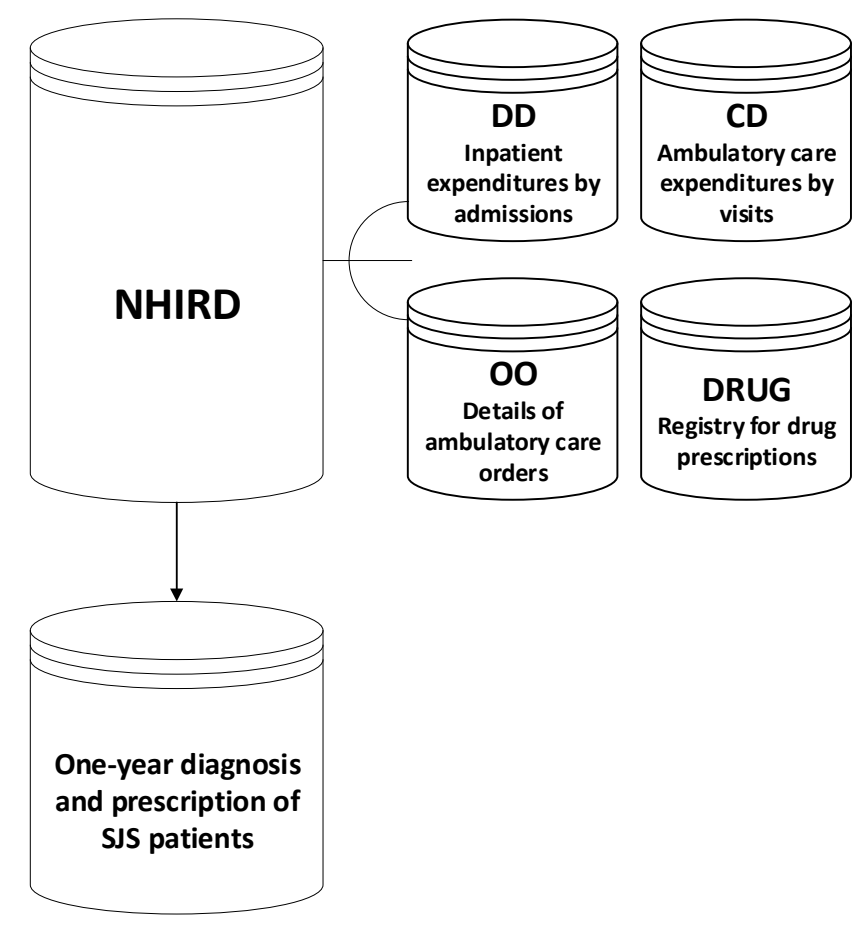

Figure 2. Data collection.

Since the highest risk of induction of SJS occurs during the first two months of treatment $[12,13,16]$, this research further extracted the diseases contracted in the two months before patients developed SJS. 
Because we retrieved the diagnosis and prescription data from only one year (2008), we were unable to retrieve the data of the preceding two months for patients who developed SJS in January and February 2008; therefore, we retrieved the in-patient data only from March-December 2008.

As shown in Table 1, from the hospital records of inpatients admitted for SJS in Taiwan in 2008, the study collected 545 patients whose hospitalization dates were from March-December and whose primary diagnosis code was SJS. We retrieved the medical records of these patients for the two months preceding hospitalization for follow-up study. The patients were distributed in different genders and age groups. There were 266 males and 279 females, with an average age of 41 years; for that time period, there were 11,626,351 males and 11,410,680 females in Taiwan [41].

Table 1. Characteristics of the study and population of Taiwan.

\begin{tabular}{ccccc}
\hline \multicolumn{3}{c}{ SJS Patients } & \multicolumn{2}{c}{ Population of Taiwan } \\
\hline Gender & & & & \\
Male & 266 & $48.81 \%$ & $11,626,351$ & $50.47 \%$ \\
Female & 279 & $51.19 \%$ & $11,410,680$ & $49.53 \%$ \\
Age & & & & \\
$0-14$ & 176 & $32.29 \%$ & $3,905,203$ & $16.95 \%$ \\
$15-64$ & 194 & $35.60 \%$ & $16,729,608$ & $72.62 \%$ \\
$\geqq 65$ & 175 & $32.11 \%$ & $2,402,220$ & $10.43 \%$ \\
& 545 & $100.00 \%$ & $23,037,031$ & $100.00 \%$ \\
\hline
\end{tabular}

\subsection{Data Pre-Processing}

To use GSP to mine the disease sequential patterns (disease patterns) and the drug-taken sequential patterns (drug patterns), we had to convert the format of the diagnosis and prescription medication data according to Tables 2 and 3, respectively.

Table 2. List of disease categories. (Based on ICD-9-CM).

\begin{tabular}{cc}
\hline Disease Category Code & Disease Category Name \\
\hline 1 & Infectious and parasitic diseases \\
3 & Neoplasms \\
4 & Endocrine, nutritional and metabolic diseases and immunity disorders \\
5 & Diseases of the blood and blood-forming organs \\
6 & Mental disorders \\
7 & Diseases of the nervous system and sense organs \\
8 & Diseases of the circulatory system \\
9 & Diseases of the respiratory system \\
10 & Diseases of the digestive system \\
11 & Diseases of the genitourinary system \\
12 & Complications of pregnancy, childbirth, and the puerperium \\
14 & Diseases of the skin and subcutaneous tissue \\
15 & Congenital anomalies \\
16 & Ciseases of the musculoskeletal system and connective tissue \\
17 & Certain conditions originating in the perinatal period \\
19 & Symptoms, signs, and ill-defined conditions \\
& Injury and poisoning \\
\hline
\end{tabular}

Table 2 presents the list of disease categories. It is based on the International Classification of Diseases, Ninth Revision, Clinical Modification (ICD-9-CM) codes [42]. 
Table 3. List of medication categories.

\begin{tabular}{cc}
\hline Medication Category Code & Medication Category Name \\
\hline A & Aminoglycoside antibiotics \\
B & Carbonic anhydrase inhibitors (CAI) diuretics \\
C & Fluoroquinolones antibiotics \\
D & H2-antagonists for peptic ulcer \\
E & Lincosamides antibiotics \\
F & Nitroimidazole antibiotics \\
G & Penicillin antibiotics \\
H & Theophylline bronchodilators \\
I & Tetracycline antibiotics \\
J & Muscle relaxants \\
K & Anti-tuberculous agents \\
L & Anti-fungal medications \\
M & Anticonvulsant agents \\
P & Erythromycin antibiotics \\
Q & Lipid-lowering medications \\
R & Antihypertensive medications \\
T & Sulfonamides \\
U & Cephalosporin antibiotics \\
\hline
\end{tabular}

According to past research, more than 100 medications of various classes have been associated with SJS [12,13]. This study focused on the frequently-implicated medications, based on a previous study [29]. Table 3 lists the drug category codes and names.

The original data of the patients, which were retrieved from each patient's medical record for the 2 months preceding hospitalization, included information such as the patient's ID, dates of hospitalization, dates of outpatient visits, disease codes, and drug details. After preprocessing the diagnosis and prescription data, we obtained the following format.

The patients' outpatient records could be considered as shown in Table 4.

Table 4. Examples of patients' outpatient records.

\begin{tabular}{cccc}
\hline Patient ID & Number of Outpatient Visits & Disease Category Codes & Medication Category Codes \\
\hline \multirow{2}{*}{$\mathrm{P}_{1}$} & 1 & 8 & $\mathrm{~K}$ \\
& 2 & $3,7,16$ & $\mathrm{M}, \mathrm{T}$ \\
& 3 & $8,10,12$ & $\mathrm{E}$ \\
\multirow{2}{*}{$\mathrm{P}_{2}$} & 4 & $8,16,17$ & $\mathrm{C}, \mathrm{T}$ \\
\hline \multirow{2}{*}{$\mathrm{P}_{3}$} & 1 & 8,17 & $\mathrm{M}, \mathrm{T}$ \\
& 2 & 8 & $\mathrm{~T}$ \\
\hline \multirow{2}{*}{$\mathrm{P}_{4}$} & 1 & $6,8,15$ & $\mathrm{H}, \mathrm{T}$ \\
& 2 & 12 & $\mathrm{G}$ \\
\hline & 1 & 8,12 & $\mathrm{D}, \mathrm{T}$ \\
& 2 & 3,8 & $\mathrm{H}$ \\
& 3 & $6,7,9$ & $\mathrm{~T}, \mathrm{U}$ \\
\hline
\end{tabular}

Then the patients' outpatient sequences could be considered as shown in Table 5. For example, the third outpatient visit of $\mathrm{P}_{1}$ is presented as " $8,10,12$ " in Table 4 and as "( 81012$)$ " in Table 5.

After pre-processing the out-patient medication records for SJS patients $(D)$, we classified them according to the number of outpatient visits before SJS hospitalization. Therefore, $D=\left\{D_{i}\right\}, D_{i}$ is the group of SJS patients with $i$ times of outpatient visits before hospitalization. 
Table 5. Examples of patients' outpatient sequences.

\begin{tabular}{ccc}
\hline Patient ID & Disease Sequence & Medication Sequence \\
\hline $\mathrm{P}_{1}$ & $<(8)(3716)(81012)(81617)>$ & $<(\mathrm{K})(\mathrm{M} \mathrm{T})(\mathrm{E})(\mathrm{C} \mathrm{T})>$ \\
\hline $\mathrm{P}_{2}$ & $<(817)(8)>$ & $<(\mathrm{M} \mathrm{T})(\mathrm{T})>$ \\
\hline $\mathrm{P}_{3}$ & $<(6815)(12)>$ & $<(\mathrm{H} \mathrm{T})(\mathrm{G})>$ \\
\hline $\mathrm{P}_{4}$ & $<(812)(38)(679)(812)>$ & $<(\mathrm{D} \mathrm{T})(\mathrm{H})(\mathrm{T} \mathrm{U})(\mathrm{T})>$ \\
\hline
\end{tabular}

As shown in Table 6, 15 groups had outpatient visit numbers of $1-13,15$, and 19. Consequently, $D$ $=\left\{D_{i}\right\}, i=1-13,15$, and 19. Here, $i$ is also called the sequence pattern length of outpatient visits before SJS hospitalization.

Table 6. Number of SJS patients with different numbers of outpatient visits.

\begin{tabular}{cc}
\hline $\begin{array}{c}\text { Number of Outpatient Visits } \\
\text { (Sequential Pattern Length) }\end{array}$ & Number of SJS Patients \\
\hline 1 & $129 *$ \\
2 & $115^{*}$ \\
3 & $107^{*}$ \\
4 & $71^{*}$ \\
5 & 44 \\
6 & 20 \\
7 & 22 \\
8 & 11 \\
9 & 8 \\
10 & 6 \\
11 & 5 \\
12 & 3 \\
13 & 2 \\
15 & 1 \\
19 & 1 \\
\hline Total & 545 \\
\hline
\end{tabular}

In this study, support for a sequence is defined as the fraction of total patients who support this sequence. The minimum support is defined as the smallest fraction that is specified by a user. The minimum support was set at $10 \%$ in this research, so only D1 to D4 met the requirement. That is, the patients could develop SJS without many exposures to the suspected medications. Subsequently, we focused the analysis on the first four SJS patient groups $(\mathrm{Dt}, \mathrm{t}=1,2, \ldots, 4)$.

\subsection{Mining Sequential Patterns of ContractedDiseases}

The sequential pattern mining problem was first introduced by Agrawal and Srikant in 1995 [43]: Given a large database of customer transactions, the problem of mining sequential patterns is to find the maximal sequences among all sequences that have a certain user-specified minimum support. The goal of sequential pattern mining is to find all of the frequent sequences.

The Sequential Pattern Mining Framework (SPMF) is an open-source data mining library specialized in pattern mining, and it offers implementations of more than 120 data mining algorithms [44]. This study used the GSP algorithm from SPMF to discover from NHIRD data the most frequent sequential patterns of diseases and prescriptions before the development of SJS. GSP can quickly meet this requirement.

The GSP algorithm used in this study is presented in Figure 3. 


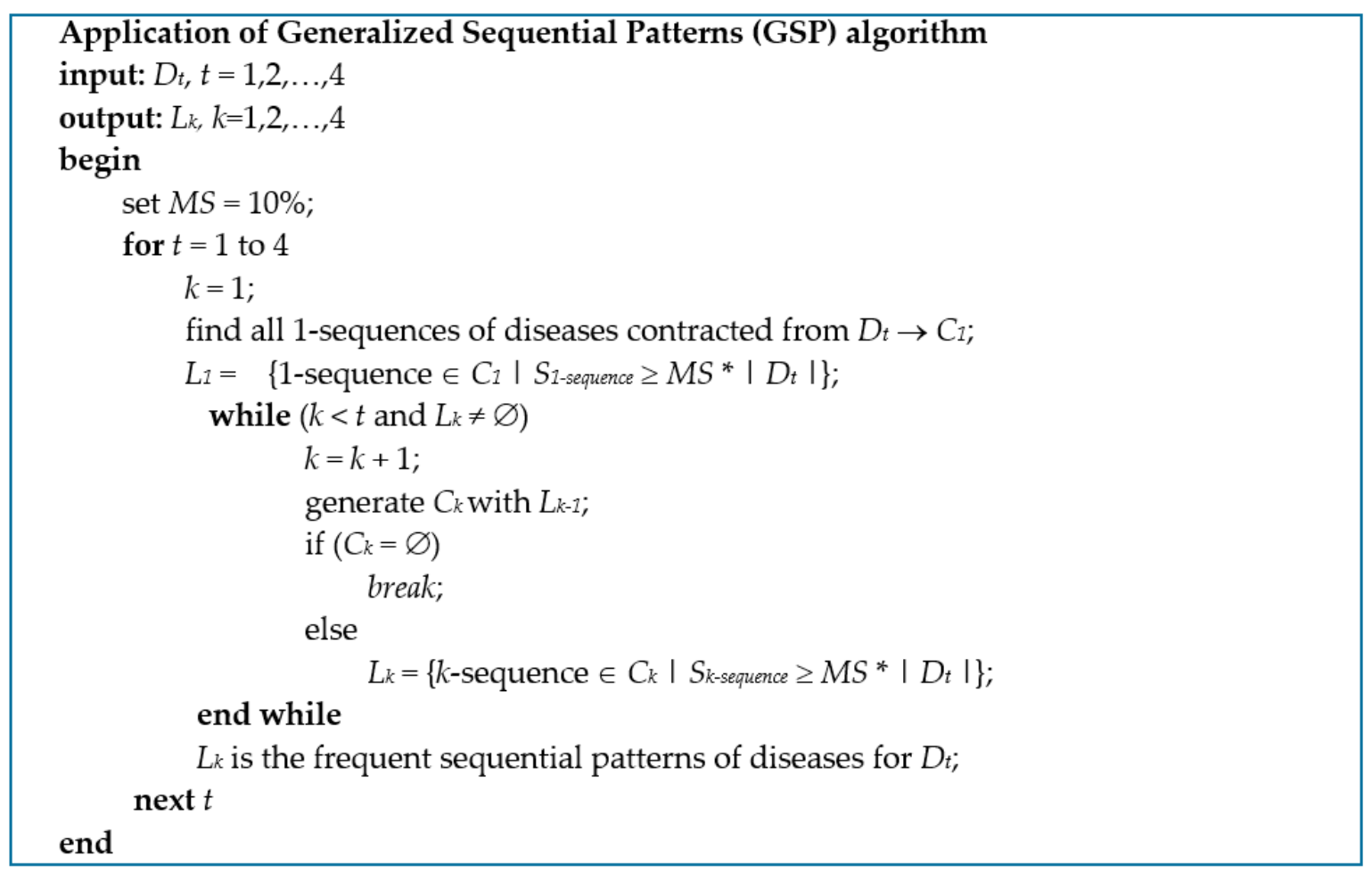

Figure 3. The pseudocode of the GSP algorithm to find the sequential patterns of diseases.

In the beginning, we discovered the sequential patterns of diseases contracted, or disease patterns, before patients developed SJS. Then we mined these disease patterns in groups 1-4, group-by-group, because only these groups met the requirement of minimum support $=10 \%$. For example, in group 1 , the disease pattern was $\langle(8)>$; in group 2 , the disease pattern was $\langle(8)(8)>$, and so on. That is, $<(8)>$ was a frequent disease pattern of pattern length $1 ;<(8)(8)>$ was a frequent disease pattern of pattern length 2 , and so on.

\subsection{Mining Sequential Patterns of Medications Prescribed}

Afterwards, for each disease pattern identified in groups of different lengths, we also used GSP (the algorithm we used in Figure 3, but with the disease sequence changed to medication sequence) to mine the sequential patterns of medications prescribed, or drug patterns.

For example, in disease pattern $<(8)>$ of group 1, the drug patterns were $\langle(\mathrm{T})>$ and $\langle(\mathrm{H})>$; in disease pattern $\langle(8)(8)>$ of group 2 , the drug patterns were $\langle(\mathrm{T})(\mathrm{T})\rangle,\langle(\mathrm{U})(\mathrm{T})\rangle$ and $\langle(\mathrm{T} \mathrm{U})(\mathrm{T})\rangle$, and so on. That is, drugs $(\mathrm{T})$ and $(\mathrm{H})$ were frequently prescribed in disease pattern $<(8)>$ of pattern length 1 ; drugs $<(\mathrm{T})(\mathrm{T})>,<(\mathrm{U})(\mathrm{T})>$ and $<(\mathrm{T} \mathrm{U})(\mathrm{T})>$ were frequent drug patterns in disease pattern $<(8)(8)>$ of pattern length 2 , and so on. Moreover, (T U) means that the patients were prescribed the drugs (T) and (U) at the same time, as shown in Table 5.

\subsection{Statistical Analysis}

In addition to the above-mentioned results of disease patterns and medication patterns, we divided the patients into different age groups in both patterns. Thus, significant associations among age groups were examined with Pearson's chi-square test, calculated in SPSS (v.23.0.0.0, IBM Inc., Armonk, NY, U.S.A.). Comparisons of variables were made appropriately, using trial-and-error to tune the variables. A $p$-value less than 0.05 was set as the level of statistical significance.

Then we discussed the explanations of both significant and insignificant age group differences of the patterns with experts, namely, an expert clinician on the author's team and specialized physicians. We especially focused on the medical practice to explain possible reasons for the results. 


\section{Results}

As shown in Table 1, only $16.95 \%$ of the population of Taiwan was aged $0-14$, yet this age group comprised $32.29 \%$ of the SJS patients. The percentage of the population aged 15-64 was $72.62 \%$, and this group comprised $35.60 \%$ of the SJS patients. The percentage of the population aged above 65 was $10.43 \%$, yet this age group comprised $32.11 \%$ of the SJS patients. This shows that children and the elderly are more susceptible to SJS.

The above results also showed that patients could develop SJS regardless of gender and age. Therefore, physicians in pediatrics, geriatrics, obstetrics and gynecology, and other specializations should pay attention to medication safety for patients of all ages and genders.

As shown in Table 6, the study analyzed the groups whose lengths were under 4, and the GSP algorithm was used to identify the disease patterns according to the classification of diseases in Table 2 . Then we used chi-square and Fisher's exact test, with a 95\% confidence interval, to infer whether there was a significant difference. The results of the analysis are shown in Table 7.

Table 7. The mined sequential patterns of diseases contracted before the development of SJS.

\begin{tabular}{cccccc}
\hline \multirow{2}{*}{$\begin{array}{c}\text { Number of } \\
\text { Outpatient Visits }\end{array}$} & N (\%) & \multicolumn{4}{c}{ Stratified by Age, $\mathbf{n}(\mathbf{\%})$} \\
\cline { 3 - 6 } & & $\mathbf{0 - 1 4}$ & $\mathbf{1 5 - 6 4}$ & $\geq \mathbf{6 5}$ & $\boldsymbol{p}$ Value \\
\hline Pattern length $=1$ & 129 & $56(43.41)$ & $46(35.66)$ & $27(20.93)$ & \\
\hline$<(8)>$ & $51(39.53)$ & $34(66.67)$ & $14(27.45)$ & $3(5.88)$ & $* 0.000$ \\
$<(12)>$ & $30(23.26)$ & $11(36.67)$ & $12(40.00)$ & $7(23.33)$ & 0.594 \\
$<(16)>$ & $23(17.83)$ & $10(43.48)$ & $7(30.43)$ & $6(26.09)$ & 0.654 \\
$<(9)>$ & $17(13.18)$ & $5(29.41)$ & $7(41.18)$ & $5(29.41)$ & 0.867 \\
$<(7)>$ & $15(11.63)$ & & $6(40.00)$ & $9(60.00)$ & NC \\
$<(6)>$ & $14(10.85)$ & $3(21.43)$ & $7(50.00)$ & $4(28.57)$ & 0.499 \\
\hline Pattern length $=2$ & 115 & $39(33.91)$ & $43(37.39)$ & $33(28.70)$ & \\
\hline$<(8)(8)>$ & $23(20.00)$ & $16(69.57)$ & $6(26.09)$ & $1(4.35)$ & $* 0.000$ \\
$<(8)(12)>$ & $14(12.17)$ & $12(85.71)$ & $2(14.29)$ & & NC \\
\hline Pattern length $=3$ & 107 & $37(34.58)$ & $33(30.84)$ & $37(34.58)$ & \\
\hline$<(8)(8)(8)>$ & $14(13.08)$ & $12(85.71)$ & & $2(14.29)$ & NC \\
\hline Pattern length $=4$ & 71 & $24(33.80)$ & $21(29.58)$ & $26(36.62)$ & \\
\hline$<(8)(8)(8)(8)>$ & $13(18.31)$ & $11(84.62)$ & & $2(15.38)$ & NC \\
\hline
\end{tabular}

1. Chi-square and Fisher's exact test were used for categorical data with a significance level of $p<0.05 .2$. ${ }^{*}$ Statistically significant $(p<0.05)$. 3. NC denotes not calculated; some age groups had 0 cases, or the calculation suggested that our sample size in the group might not be large enough to detect a significant association among groups.

For the length 1 group, there were six disease patterns whose support ranged from $10.85 \%$ to $39.53 \%$ : Respiratory system $\langle(8)>$, skin and subcutaneous tissue $\langle(12)>$, symptoms, signs, and ill-defined conditions $\langle(16)>$, digestive system $\langle(9)>$, circulatory system $\langle(7)>$, and nervous system and sense organs $<(6)>$.

Obviously, some patients developed SJS after they were exposed to one highly suspected drug for one treatment.

Nearly $40 \%$ of patients $(N=51)$, had respiratory system disease $<(8)>$. In contrast, more than $20 \%$ of patients, up to 30 people, had skin and subcutaneous tissue disease $<(12)>$. Among them, only four patients contracted both of the diseases, so we deducted the four repeated patients. This left 77 patients in total; up to $60 \%$ of these patients had one of the two diseases, which shows the high possibility of developing SJS.

For respiratory system disease $<(8)>$, there was a significant difference in age $(p<0.05)$. Thirty-four patients $(66.67 \%)$ were under the age of 14 . For circulatory system disease $<(7)>$, no patients were 
younger than 14 years old, and nine of them $(60 \%)$ were older than 65 years. The distributions of the patients in other disease patterns of length 1 were more equal, and no significant differences were found.

In the length 2 group, there were two disease patterns, $<(8)(8)>$ and $\langle(8)(12)>$, with support of $20 \%$ and $12.17 \%$. The diseases were respiratory system (8) and skin and subcutaneous tissue (12), which were the same as in the length 1 group. We found that the two diseases had the highest ratios in both groups.

Regarding the age distribution, the $p$-value of the pattern of $<(8)(8)>$ respiratory system was less than 0.05 , indicating a significant difference in age. Sixteen of the patients $(69.57 \%)$ were under the age of 14 . For the pattern of $<(8)(12)>$ respiratory system and skin diseases, 12 patients $(85.71 \%)$ were under the age of 14 , while no patients were over the age of 65 . The above two patterns were found mostly in patients under the age of 14 , so they should be paid more attention during treatment.

In the length 3 group, there was only one pattern, $<(8)(8)(8)>$, and the support was $13.08 \%$. Twelve patients $(85.71 \%)$ were under 14 years old. The other two patients $(14.29 \%)$ were over 65 years old. In the length 4 group, there was only one pattern, $<(8)(8)(8)(8)>$, and the support was $18.31 \%$. Eleven patients $(84.62 \%)$ were under the age of 14 ; the other two patients $(15.38 \%)$ were over 65 years old.

In the length 3 and 4 groups, respiratory system disease (8) was repeated in the patterns. There were no patients in some age groups, so Pearson's chi-square test was not applicable. However, we could find obvious differences in the age groups, and the distributions of the age groups of the two patterns were similar. That is, most of the patients were under 14 years old, the remaining patients were older than 64 years, and none were aged 15-64 years.

To ensure medication safety, physicians should pay attention to what drugs they prescribe when the above-mentioned situation occurs.

Figure 4 presents the sequential patterns according to the different pattern lengths and disease categories, and the level of support is indicated by the size of the circle. As shown in the chart, respiratory system disease (8) was the highest one of the different sequential pattern lengths. For length $>1$, all the patterns were associated with respiratory system disease. Thus, respiratory system disease has a close relationship with SJS.

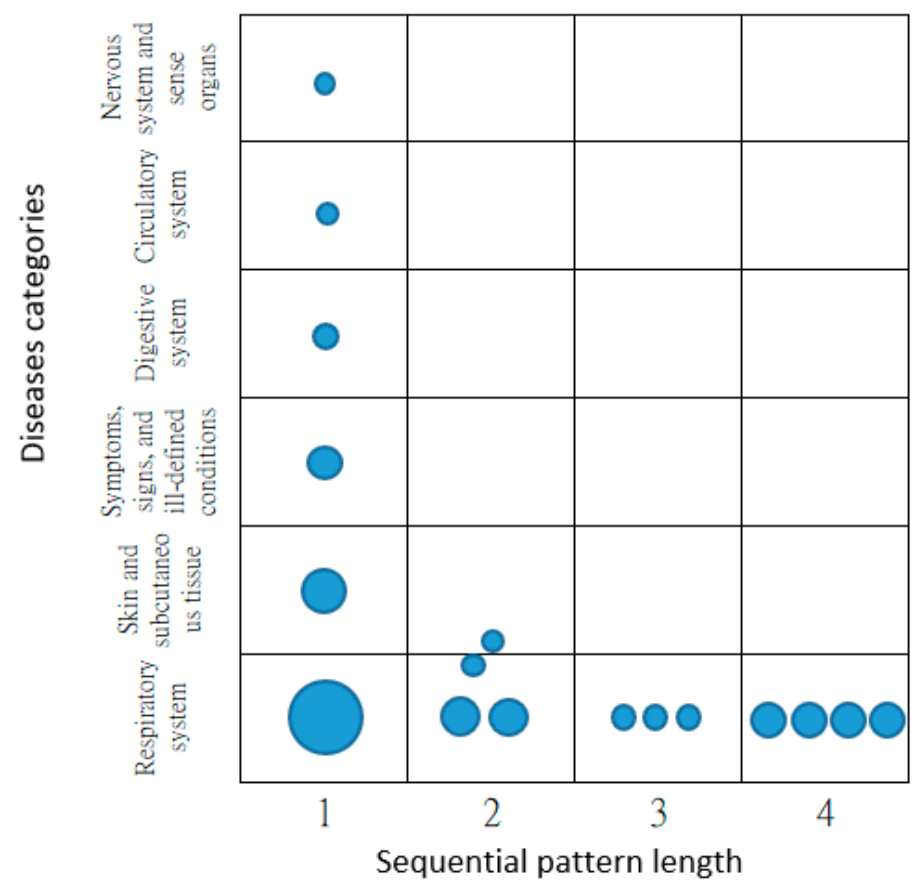

Figure 4. Disease categories by sequential pattern length.

Based on the different lengths of the sequential patterns of diseases contracted, we used the medication category codes (Table 3 ) and identified the drug patterns. They are shown in Table 8. 
Table 8. The mined disease sequential patterns of medications prescribed before the development of SJS.

\begin{tabular}{|c|c|c|c|c|c|}
\hline \multirow{2}{*}{ Drug-Taken } & \multirow{2}{*}{$\mathbf{N}(\%)$} & \multicolumn{4}{|c|}{ Stratified by Age n (\%) } \\
\hline & & 0-14 & $15-64$ & $\geq 65$ & $p$ Value \\
\hline \multicolumn{6}{|l|}{$\begin{array}{l}\text { Pattern length = } 1 \\
\text { Disease patterns: }\end{array}$} \\
\hline$<(8)>$ Respiratory system & 51 & $34(66.67)$ & $14(27.45)$ & $3(5.88)$ & * 0.000 \\
\hline$<(\mathrm{T})>$ & $32(62.75)$ & $23(71.88)$ & $8(25.00)$ & $1(3.13)$ & * 0.000 \\
\hline$<(\mathrm{H})>$ & $9(17.65)$ & $6(66.67)$ & $2(22.22)$ & $1(11.11)$ & 0.166 \\
\hline$<(G)>$ & $6(11.76)$ & $5(83.33)$ & $1(16.67)$ & & $\mathrm{NC}$ \\
\hline$<(12)>$ Skin and subcutaneous tissue & 30 & $11(36.67)$ & $12(40.00)$ & $7(23.33)$ & 0.594 \\
\hline$<(\mathrm{T})>$ & $11(36.67)$ & $2(18.18)$ & $7(63.64)$ & $2(18.18)$ & 0.134 \\
\hline$<(\mathrm{U})>$ & $7(23.33)$ & $2(28.57)$ & $2(28.57)$ & $3(42.86)$ & 1 \\
\hline$<(\mathrm{L})>$ & $6(20.00)$ & $4(66.67)$ & $2(33.33)$ & & $\mathrm{NC}$ \\
\hline$<(G)>$ & $5(16.66)$ & & $2(40.00)$ & $3(60.00)$ & $\mathrm{NC}$ \\
\hline$<(\mathrm{D})>$ & $4(13.33)$ & & $3(75.00)$ & $1(25.00)$ & $\mathrm{NC}$ \\
\hline$<(\mathrm{I})>$ & $4(13.33)$ & $2(50.00)$ & $2(50.00)$ & & $\mathrm{NC}$ \\
\hline$<(\mathrm{T} \mathrm{U})>$ & $3(10.00)$ & & $2(66.67)$ & $1(33.33)$ & $\mathrm{NC}$ \\
\hline$<(16)>$ Symptoms, signs, and ill-defined conditions & 23 & $10(43.48)$ & $7(30.43)$ & $6(26.09)$ & 0.654 \\
\hline$<(\mathrm{T})>$ & $16(69.57)$ & $7(43.75)$ & $6(37.5)$ & $3(18.75)$ & 0.541 \\
\hline$<(\mathrm{U})>$ & $4(17.39)$ & $1(25.00)$ & & $3(75.00)$ & $\mathrm{NC}$ \\
\hline$<(9)>$ Digestive system & 17 & $5(29.41)$ & $7(41.18)$ & $5(29.41)$ & 0.867 \\
\hline$<(\mathrm{T})>$ & $9(52.94)$ & $2(22.22)$ & $5(55.56)$ & $2(22.22)$ & 0.531 \\
\hline$<(\mathrm{U})>$ & $3(17.65)$ & & $3(100.00)$ & & $\mathrm{NC}$ \\
\hline$<(\mathrm{T} \mathrm{U})>$ & $3(17.65)$ & & $3(100.00)$ & & $\mathrm{NC}$ \\
\hline$<(\mathrm{D})>$ & $2(11.76)$ & & $1(50.00)$ & $1(50.00)$ & $\mathrm{NC}$ \\
\hline$<(G)>$ & $2(11.76)$ & $1(50.00)$ & $1(50.00)$ & & $\mathrm{NC}$ \\
\hline$<(\mathrm{H})>$ & $2(11.76)$ & $1(50.00)$ & & $1(50.00)$ & $\mathrm{NC}$ \\
\hline$<(\mathrm{M})>$ & $2(11.76)$ & & $1(50.00)$ & $1(50.00)$ & $\mathrm{NC}$ \\
\hline$<(7)>$ Circulatory system & 15 & & $6(40.00)$ & $9(60.00)$ & $\mathrm{NC}$ \\
\hline$<(\mathrm{R})>$ & $9(60.00)$ & & $1(11.11)$ & $8(88.89)$ & $\mathrm{NC}$ \\
\hline$<(\mathrm{T})>$ & $8(53.33)$ & & $4(50.00)$ & $4(50.00)$ & $\mathrm{NC}$ \\
\hline$<(\mathrm{R} \mathrm{T})>$ & $4(26.67)$ & & & $4(100.00)$ & $\mathrm{NC}$ \\
\hline$<(\mathrm{M})>$ & $3(20.00)$ & & $2(66.67)$ & $1(33.33)$ & $\mathrm{NC}$ \\
\hline$<(\mathrm{J})>$ & $2(13.33)$ & & $2(100.00)$ & & $\mathrm{NC}$ \\
\hline$<(6)>$ Nervous system and sense organs & 14 & $3(21.43)$ & $7(50.00)$ & $4(28.57)$ & 0.499 \\
\hline$<(\mathrm{M})>$ & $6(42.86)$ & $1(16.67)$ & $4(66.67)$ & $1(16.67)$ & 0.383 \\
\hline$<(\mathrm{T})>$ & $6(42.86)$ & $1(16.67)$ & $2(33.33)$ & $3(50.00)$ & 0.877 \\
\hline$<(\mathrm{U})>$ & $3(21.43)$ & & $3(100.00)$ & & $\mathrm{NC}$ \\
\hline$<(\mathrm{T} \mathrm{U})>$ & $2(14.29)$ & & $2(100.00)$ & & $\mathrm{NC}$ \\
\hline \multicolumn{6}{|l|}{$\begin{array}{c}\text { Pattern length }=2 \\
\text { Disease patterns: }\end{array}$} \\
\hline$<(8)(8)>$ Respiratory system & 23 & $16(69.57)$ & $6(26.09)$ & $1(4.35)$ & ${ }^{*} 0.000$ \\
\hline$<(\mathrm{T})(\mathrm{T})>$ & $13(56.52)$ & $10(76.92)$ & $3(23.08)$ & & $\mathrm{NC}$ \\
\hline$<(\mathrm{U})(\mathrm{T})>$ & 4 (17.39) & $3(75.00)$ & $1(25.00)$ & & $\mathrm{NC}$ \\
\hline$<(\mathrm{T} \mathrm{U})(\mathrm{T})>$ & $3(13.04)$ & $2(66.67)$ & $1(33.33)$ & & $\mathrm{NC}$ \\
\hline$<(8)(12)>$ Respiratory system, Skin and subcutaneous tissue & 14 & $12(85.71)$ & $2(14.29)$ & & $\mathrm{NC}$ \\
\hline$<(\mathrm{T})(\mathrm{T})>$ & $5(35.71)$ & $5(100.00)$ & & & $\mathrm{NC}$ \\
\hline$<(\mathrm{T})(\mathrm{D})>$ & $3(21.43)$ & $2(66.67)$ & $1(33.33)$ & & $\mathrm{NC}$ \\
\hline \multicolumn{6}{|l|}{$\begin{array}{l}\text { Pattern length }=3 \\
\text { Disease pattern: }\end{array}$} \\
\hline$<(8)(8)(8)>$ Respiratory system & 14 & $12(85.71)$ & & $2(14.29)$ & NC \\
\hline$<(\mathrm{T})(\mathrm{T})(\mathrm{T})>$ & $7(50.00)$ & $7(100.00)$ & & & $\mathrm{NC}$ \\
\hline$<(\mathrm{H})(\mathrm{H})(\mathrm{H})>$ & $2(15.38)$ & $2(100.00)$ & & & $\mathrm{NC}$ \\
\hline \multicolumn{6}{|l|}{$\begin{array}{l}\text { Pattern length }=4 \\
\text { Disease pattern: }\end{array}$} \\
\hline$<(8)(8)(8)(8)>$ Respiratory system & 13 & $11(84.62)$ & & $2(15.38)$ & NC \\
\hline$<(\mathrm{T})(\mathrm{T})(\mathrm{T})(\mathrm{T})>$ & $3(23.08)$ & $3(100.00)$ & & & NC \\
\hline$<(\mathrm{H})(\mathrm{H})(\mathrm{H})(\mathrm{H})>$ & $2(15.38)$ & & & $2(100.00)$ & $\mathrm{NC}$ \\
\hline$<(\mathrm{H})(\mathrm{H})(\mathrm{T})(\mathrm{T})>$ & $2(15.38)$ & $2(100.00)$ & & & $\mathrm{NC}$ \\
\hline$<(\mathrm{G} \mathrm{T})(\mathrm{T})(\mathrm{T})(\mathrm{T})>$ & $2(15.38)$ & $2(100.00)$ & & & $\mathrm{NC}$ \\
\hline
\end{tabular}

1. Chi-square and Fisher's exact test were used for categorical data with a significance level of $p<0.05 .2 .{ }^{*}$ Statistically significant $(p<0.05)$. 3. NC denotes not calculated; some age groups had 0 cases, or the calculations suggested that our sample size in a group might not be large enough to detect a significant association among groups. 
Six disease patterns were found in the length 1 group. Examination of these drug patterns revealed NSAIDs (T) in every disease pattern, and it was the medication with the highest frequency for most disease patterns.

The second one was cephalosporin antibiotics (U). It was not found in the disease patterns of respiratory system $\langle(8)>$ and circulatory system disease $\langle(7)>$, but it was prescribed in the other four patterns. These four patterns, particularly the pattern of symptoms, signs, and ill-defined conditions $<(16)>$, only had these two medicines. Moreover, (T U) indicates that the two medications were prescribed at the same time. It also appears in three patterns: Skin $\langle(12)\rangle$, digestive system $\langle(9)>$, and nervous system $<(6)>$. As a result, the two medications $(\mathrm{T})(\mathrm{U})$ had a significant impact on SJS patients with one outpatient visit.

For the length 1 group, all the drug patterns of the disease patterns indicated that even patients who were prescribed suspected drugs only once could develop SJS; this point is very important for physicians to consider.

In the length 2 group, there were two disease patterns, $<(8)(8)>$ and $<(8)(12)>$. For pattern $<(8)$ $(8)>$, the patients were prescribed only two medications, (T) (U); they could be taken at the same time or separately. For pattern $<(8)(12)>$, there were two drug patterns, $<(T)(T)>$ and $<(T)(D)>$. Except for H2-antagonists for peptic ulcer (D), the patients were all prescribed (T). Therefore, $(T)$ is highly associated with SJS.

In the length 3 group, there was only one disease pattern, $<(8)(8)(8)>$ respiratory system disease, but there were two drug patterns, $<(\mathrm{T})(\mathrm{T})(\mathrm{T})>$ and $<(\mathrm{H})(\mathrm{H})(\mathrm{H})>$. Drug $(\mathrm{H})$ comprise theophylline bronchodilators. These two drug patterns were both prescribed three times. Patients were also prescribed $(\mathrm{T})$ again in this disease pattern.

In the length 4 group, there was only one disease pattern, $<$ (8) (8) (8) (8) $>$ respiratory system disease, but there were four drug patterns, $\langle(\mathrm{T})(\mathrm{T})(\mathrm{T})(\mathrm{T})>,\langle(\mathrm{H})(\mathrm{H})(\mathrm{H})(\mathrm{H})>,\langle(\mathrm{H})(\mathrm{H})(\mathrm{T})(\mathrm{T})>$, and $<(\mathrm{G} \mathrm{T})(\mathrm{T})(\mathrm{T})(\mathrm{T})>$. The former three patterns, $\langle(\mathrm{T})(\mathrm{T})(\mathrm{T})(\mathrm{T})>,<(\mathrm{H})(\mathrm{H})(\mathrm{H})(\mathrm{H})>$, and $<(\mathrm{H})$ $(\mathrm{H})(\mathrm{T})(\mathrm{T})>$, were the same as those in the length 3 group; patients were prescribed only $(\mathrm{T})$ and $(\mathrm{H})$. For the fourth pattern, $<(G \mathrm{~T})(\mathrm{T})(\mathrm{T})(\mathrm{T})>$, patients were prescribed penicillin antibiotics $(\mathrm{G})$ and NSAIDs (T) at the same time. Then the patients were prescribed $(\mathrm{T})$ three times.

Based on the above analysis of all the drug patterns and disease patterns, we found that respiratory system disease (8) frequently appeared in all the disease patterns of different lengths, and drug (T) NSAIDs was frequently taken in all the different drug patterns.

For patients with one or two outpatient visits (groups 1 and 2), Cephalosporin antibiotics (U) were frequently prescribed. For patients with three or four outpatient visits (groups 3 and 4), (U) was not frequently prescribed; instead, theophylline bronchodilators $(\mathrm{H})$ were prescribed in this situation.

\section{Discussion}

This study analyzed the data for patients grouped by age, gender, and number of outpatient visits.

As shown in Table 6, the number of prior outpatient visits for most SJS patients was less than four. This number indicates that patients can develop SJS without being exposed to the suspected medications for extended periods.

Table 1 shows the percentages of Taiwan's population aged under 14 (16.95\%), aged 15-64 (72.62\%), and aged above $65(10.43 \%)$ in 2008. The percentages of young people and elderly people were below $20 \%$. However, the percentage of SJS patients under the age of 14 was $32.29 \%$, and that of SJS patients above the age of 65 was $32.11 \%$. This shows that in Taiwan, these two age groups have a high risk of developing SJS, which is consistent with previous studies.

The percentage of female SJS patients was $51.19 \%$, which is slightly higher than that of males, and this is also consistent with other studies.

However, our gender and age distributions showed that males and females of all ages can develop SJS. Therefore, physicians of all specialties, including pediatrics and geriatrics, and even obstetrics and gynecology, must be familiar with the medications they prescribe that may trigger SJS. 
This study also analyzed the specific associations between the diseases and the suspected medications. As shown in Table 8, the common cold, which is recorded as a respiratory system disease, was the most common disease and was found in every outpatient group. Its proportion was the highest among all groups. Moreover, the proportion of patients aged under 14 was higher than those of other age groups of respiratory system disease, probably because patients in this age group are more likely to visit clinics to seek treatment for the common cold.

The medications for common chronic diseases shown in Table 8 may also cause SJS. As a result, physicians must always be alert in prescribing medications for chronic conditions, as well as for acute diseases.

In Table 8, drug (T) NSAIDs can be found in all of the outpatient visit patterns; therefore, this might be the drug most commonly associated with SJS in Taiwan.

Drug (U), cephalosporin antibiotics, was prescribed only when the number of outpatient visits was less than or equal to two. This result indicates that (U) can trigger SJS after only a short exposure. For most clinical visits in Taiwan, physicians prescribe three days' worth of medicine per visit. This means (U) can trigger SJS in just six days.

On the other hand, drug $(\mathrm{H})$, theophylline bronchodilators, was prescribed in cases with outpatient visit numbers greater than or equal to three. This result indicates that $(\mathrm{H})$ triggers SJS only after being prescribed more than twice. As a result, physicians must be alert to repeated usage of cephalosporin and theophylline bronchodilators to prevent SJS.

As shown in Table 8, some medications in the group of 1 outpatient visit are particularly worthy of attention. First, drug (D), H2-antagonist, is in disease patterns $\langle(12)\rangle$ and $\langle(9)>$, but H2-antagonist is not a medicine for skin (12) or the digestive system (9). Second, drugs (H), theophylline bronchodilators, and $(\mathrm{M})$, anticonvulsant agents, are in the $\langle(9)>$ disease pattern, but theophylline bronchodilators and anticonvulsant agents are not medicines for treating (9) diseases of the digestive system. Third, drugs $(\mathrm{M})$, anticonvulsant agents, and (J), muscle relaxants, are in the $<(7)>$ disease pattern, but anticonvulsant agents and muscle relaxants are not prescribed for (7) diseases of the circulatory system.

As mentioned in the results section, drug (T) NSAIDs, was frequently prescribed in all the sequences of different lengths. For patients with three or four outpatient visits, drug $(\mathrm{H})$ was often prescribed. Therefore, when outpatient visits are frequent within a short period, physicians should pay attention not only to NSAIDs (T) but also to theophylline bronchodilators (H).

The above results may indicate that physicians in Taiwan commonly prescribe additional medications to patients besides those for their main illness. For example, H2-antagonists could be prescribed for "gastric protection" when patients are given drugs for other medical conditions. Few physicians are aware that a relatively safe drug, such as H2-antagonists, can by itself cause SJS. According to our findings, physicians should be warned of the dangers of prescribing additional drugs which are not necessary for treating the patient's main illness (though they might be prescribed because of the patient's history), for the additional drugs are associated with a higher probability of developing SJS.

However, a limitation of the present study should be mentioned. Although the National Health Insurance Database we used included all treatment records of all SJS patients in the nation, it did not contain information concerning heathy people or patients with illnesses other than SJS. Thus, no comparison with control data for specificity could be carried out. Including another dataset of the Health Insurance Database consisting of non-SJS patients as control data may be more ideal in future studies.

\section{Conclusions}

Pharmacovigilance involves the detection, assessment, understanding, and prevention of ADRs, which strain healthcare resources and, thus, have strong implications for public health. Among all the diseases caused by ADRs, SJS is the most serious one in Taiwan. By data mining of the NHIRD 
database, also known as electronic health records, we found suspected medications and diseases before patients developed SJS in Taiwan.

To summarize, we offer the information of the sequential patterns of contracting diseases and prescribing medications before SJS developed, in order to help healthcare providers to avoid more serious cases of SJS at its early stages.

Author Contributions: Conceptualization: C.O.-Y. and H.-C.W.; data curation: S.-C.C.; formal analysis: C.O.-Y., S.-C.C., Y.-C.J., and H.-C.W.; investigation: S.-C.C.; methodology: S.-C.C. and Y.-C.J.; project administration: S.-C.C.; resources: C.O.-Y. and H.-C.W.; software: S.-C.C. and Y.-C.J.; supervision: C.O.-Y. and H.-C.W.; validation: C.O.-Y., S.-C.C., and Y.-C.J.; visualization: S.-C.C.; writing—original draft: S.-C.C. and Y.-C.J.; writing—review and editing: C.O.-Y. and H.-C.W.

Acknowledgments: The authors would like to thank the Ministry of Science and Technology of the Republic of China, Taiwan, for financially supporting this research under contract no. MOST 106-2221-E-011-107.

Conflicts of Interest: The authors declare that there is no conflict of interest.

\section{References}

1. Liu, M.; Matheny, M.E.; Hu, Y.; Xu, H. Data mining methodologies for pharmacovigilance. ACM SIGKDD Explor. Newsl. 2012, 14, 35-42. [CrossRef]

2. Budnitz, D.S.; Pollock, D.A.; Weidenbach, K.N.; Mendelsohn, A.B.; Schroeder, T.J.; Annest, J.L. National surveillance of emergency department visits for outpatient adverse drug events. JAMA 2006, 296, 1858-1866. [CrossRef] [PubMed]

3. Pirmohamed, M.; Breckenridge, A.M.; Kitteringham, N.R.; Park, B.K. Adverse drug reactions. BMJ 1998, 316, 1295-1298. [CrossRef] [PubMed]

4. Lo, H.Z.; Ding, W.; Nazeri, Z. Mining adverse drug reactions from electronic health records. In Proceedings of the 2013 IEEE 13th International Conference on Data Mining Workshops, Dallas, TX, USA, 7-10 December 2013; pp. 1137-1140.

5. Trifiro, G.; Pariente, A.; Coloma, P.M.; Kors, J.A.; Polimeni, G.; Miremont-Salame, G.; Catania, M.A.; Salvo, F.; David, A.; Moore, N.; et al. Data mining on electronic health record databases for signal detection in pharmacovigilance: Which events to monitor? Pharmacoepidemiol. Drug Saf. 2009, 18, 1176-1184. [CrossRef] [PubMed]

6. World Health Organization. The Importance of Pharmacovifilance: Safety Monitoring of Medicinal Products. Available online: http://apps.who.int/medicinedocs/pdf/s4893e/s4893e.pdf (accessed on 12 October 2018).

7. Hauben, M.; Madigan, D.; Gerrits, C.M.; Walsh, L.; van Puijenbroek, E.P. The role of data mining in pharmacovigilance. Expert Opin. Drug Saf. 2005, 4, 929-948. [CrossRef] [PubMed]

8. Food and Drug Administration, Ministry of Health and Welfare. Taiwan 2017 Drug Adverse Reaction Notification Case Analysis in Taiwan. Available online: https:/www.fda.gov.tw/TC/siteList.aspx?sid=4229 (accessed on 15 October 2018).

9. Taiwan Drug Relief Foundation. Drug Relief Profile in Taiwan. Available online: http://www.tdrf.org.tw/ch/ 05knows/kno_07_main.asp?bull_id=6475 (accessed on 19 September 2017).

10. Stevens, A.M. A New eruptive fever associated with stomatitis and ophthalmia. Am. J. Dis. Child. 1922, 24, 526-533. [CrossRef]

11. Mawson, A.R.; Eriator, I.; Karre, S. Stevens-Johnson syndrome and toxic epidermal necrolysis (SJS/TEN): Could retinoids play a causative role? Med. Sci. Monit. 2015, 21, 133-143. [PubMed]

12. Roujeau, J.C.; Kelly, J.P.; Naldi, L.; Rzany, B.; Stern, R.S.; Anderson, T.; Auquier, A.; Bastuji-Garin, S.; Correia, O.; Locati, F.; et al. Medication use and the risk of Stevens-Johnson syndrome or toxic epidermal necrolysis. N. Engl. J. Med. 1995, 333, 1600-1607. [CrossRef] [PubMed]

13. Borchers, A.T.; Lee, J.L.; Naguwa, S.M.; Cheema, G.S.; Gershwin, M.E. Stevens-Johnson syndrome and toxic epidermal necrolysis. Autoimmun. Rev. 2008, 7, 598-605. [CrossRef] [PubMed]

14. Raucci, U.; Rossi, R.; da Cas, R.; Rafaniello, C.; Mores, N.; Bersani, G.; Reale, A.; Pirozzi, N.; Menniti-Ippolito, F.; Traversa, G.; et al. Stevens-Johnson syndrome associated with drugs and vaccines in children: A case-control study. PLoS ONE 2013, 8, e68231. [CrossRef] [PubMed] 
15. Aihara, M.; Kano, Y.; Fujita, H.; Kambara, T.; Matsukura, S.; Katayama, I.; Azukizawa, H.; Miyachi, Y.; Endo, Y.; Asada, H.; et al. Efficacy of additional i.v. immunoglobulin to steroid therapy in Stevens-Johnson syndrome and toxic epidermal necrolysis. J. Dermatol. 2015, 42, 768-777. [CrossRef] [PubMed]

16. Harr, T.; French, L.E. Toxic epidermal necrolysis and Stevens-Johnson syndrome. Orphanet J. Rare Dis. 2010, 5, 39. [CrossRef] [PubMed]

17. Genetic and Rare Diseases Information Center (GARD); U.S. Department of Health \& Human Services. Stevens-Johnson Syndrome/Toxic Epidermal Necrolysis. Available online: https:/rarediseases.info.nih.gov/ diseases/7700/stevens-johnson-syndrome (accessed on 14 October 2018).

18. Garcia-Doval, I.; LeCleach, L.; Bocquet, H.; Otero, X.L.; Roujeau, J.C. Toxic epidermal necrolysis and Stevens-Johnson syndrome: Does early withdrawal of causative drugs decrease the risk of death? Arch. Dermatol. 2000, 136, 323-327. [CrossRef] [PubMed]

19. Sweileh, W.M. Bibliometric analysis of literature on toxic epidermal necrolysis and Stevens-Johnson syndrome: 1940-2015. Orphanet J. Rare Dis. 2017, 12, 14. [CrossRef] [PubMed]

20. Ward, K.E.; Archambault, R.; Mersfelder, T.L. Severe adverse skin reactions to nonsteroidal antiinflammatory drugs: A review of the literature. Am. J. Health Syst. Pharm. 2010, 67, 206-213. [CrossRef] [PubMed]

21. Abe, J.; Umetsu, R.; Mataki, K.; Kato, Y.; Ueda, N.; Nakayama, Y.; Hane, Y.; Matsui, T.; Hatahira, H.; Sasaoka, S. Analysis of Stevens-Johnson syndrome and toxic epidermal necrolysis using the Japanese Adverse Drug Event Report database. J. Pharm. Health Care Sci. 2016, 2, 14. [CrossRef] [PubMed]

22. Pereira, F.A.; Mudgil, A.V.; Rosmarin, D.M. Toxic epidermal necrolysis. J. Am. Acad. Dermatol. 2007, 56, 181-200. [CrossRef] [PubMed]

23. Suwarsa, O.; Yuwita, W.; Dharmadji, H.P.; Sutedja, E. Stevens-Johnson syndrome and toxic epidermal necrolysis in Dr. Hasan Sadikin General Hospital Bandung, Indonesia from 2009-2013. Asia Pac. Allergy 2016, 6, 43-47. [CrossRef] [PubMed]

24. Tan, S.K.; Tay, Y.K. Profile and pattern of Stevens-Johnson syndrome and toxic epidermal necrolysis in a general hospital in Singapore: Treatment outcomes. Acta Derm. Venereol. 2012, 92, 62-66. [CrossRef]

25. Aroke, D.; Tchouakam, D.N.; Awungia, A.T.; Mapoh, S.Y.; Ngassa, S.N.; Kadia, B.M. Ivermectin induced Steven-Johnsons syndrome: Case report. BMC Res. Notes 2017, 10, 179. [CrossRef]

26. Abe, R. Toxic epidermal necrolysis and Stevens-Johnson syndrome: Soluble Fas ligand involvement in the pathomechanisms of these diseases. J. Dermatol. Sci. 2008, 52, 151-159. [CrossRef] [PubMed]

27. Haddad, C.; Sidoroff, A.; Kardaun, S.H.; Mockenhaupt, M.; Creamer, D.; Dunant, A.; Roujeau, J.C. Stevens-Johnson syndrome/toxic epidermal necrolysis: Are drug dictionaries correctly informing physicians regarding the risk? Drug Saf. 2013, 36, 681-686. [CrossRef] [PubMed]

28. Chung, W.H.; Hung, S.I.; Yang, J.Y.; Su, S.C.; Huang, S.P.; Wei, C.Y.; Chin, S.W.; Chiou, C.C.; Chu, S.C.; Ho, H.C.; et al. Granulysin is a key mediator for disseminated keratinocyte death in Stevens-Johnson syndrome and toxic epidermal necrolysis. Nat. Med. 2008, 14, 1343-1350. [CrossRef] [PubMed]

29. Ou-Yang, C.; Agustianty, S.; Wang, H.C. Developing a data mining approach to investigate association between physician prescription and patient outcome-A study on re-hospitalization in Stevens-Johnson Syndrome. Comput. Methods Progr. Biomed. 2013, 112, 84-91. [CrossRef] [PubMed]

30. Brook, U. Stevens-Johnson syndrome and abnormal root development: A case report. Int. J. Paediatr. Dent. 1994, 4, 101-103. [CrossRef] [PubMed]

31. Brook, U.; Singer, L.; Fried, D. Development of severe Stevens-Johnson syndrome after administration of slow-release theophylline. Pediatr. Dermatol. 1989, 6, 126-129. [CrossRef] [PubMed]

32. Rzany, B.; Mockenhaupt, M.; Holländer, N.; Stocker, U.; Mueller, J.; Baur, S.; Schöpf, E. Stevens-Johnson syndrome (SJS) and toxic epidermal necrolysis (TEN): Evaluation for drug risk based on sale numbers in defined daily doses (DDD). Example of the H2-antagonists. Pharmacoepidemiol. Drug Saf. 1995, 4, $207-212$. [CrossRef]

33. Lin, C.C.; Wu, J.C.; Huang, D.F.; Huang, Y.S.; Huang, Y.H.; Huo, T.I.; Chang, F.Y.; Lee, S.D. Ranitidine-related Stevens-Johnson syndrome in patients with severe liver diseases: A report of two cases. J. Gastroenterol. Hepatol. 2001, 16, 481-483. [CrossRef]

34. Mockenhaupt, M.; Viboud, C.; Dunant, A.; Naldi, L.; Halevy, S.; Bavinck, J.N.B.; Sidoroff, A.; Schneck, J.; Roujeau, J.C.; Flahault, A. Stevens-Johnson syndrome and toxic epidermal necrolysis: Assessment of medication risks with emphasis on recently marketed drugs. The EuroSCAR-study. J. Investig. Dermatol. 2008, 128, 35-44. [CrossRef] 
35. Chung, W.H.; Hung, S.I.; Hong, H.S.; Hsih, M.S.; Yang, L.C.; Ho, H.C.; Wu, J.Y.; Chen, Y.T. Medical genetics: A marker for Stevens-Johnson syndrome. Nature 2004, 428, 486. [CrossRef]

36. Hung, S.-I.; Chung, W.-H.; Jee, S.-H.; Chen, W.-C.; Chang, Y.-T.; Lee, W.-R.; Hu, S.-L.; Wu, M.-T.; Chen, G.-S.; Wong, T.-W.; et al. Genetic susceptibility to carbamazepine-induced cutaneous adverse drug reactions. Pharmacogenet. Genom. 2006, 16, 297-306. [CrossRef] [PubMed]

37. Food and Drug Administration, Ministry of Health and Welfare. Taiwan International Quality Management Strategy for Drug Quality. Available online: https://www.fda.gov.tw/TC/siteList.aspx?sid=2013 (accessed on 8 March 2017).

38. Srikant, R.; Agrawal, R. Mining Sequential Patterns: Generalizations and Performance Improvements; Springer: Berlin/Heidelberg, Germany, 1996; pp. 1-17.

39. Strom, B.L.; Carson, J.L.; Halpern, A.C.; Schinnar, R.; Snyder, E.S.; Stolley, P.D.; Shaw, M.; Tilson, H.H.; Joseph, M.; Dai, W.S.; et al. Using a claims database to investigate drug-induced Stevens-Johnson syndrome. Stat. Med. 1991, 10, 565-576. [CrossRef] [PubMed]

40. Hsiao, F.Y.; Yang, C.L.; Huang, Y.T.; Huang, W.F. Using Taiwan's national health insurance research databases for pharmacoepidemiology research. J. Food Drug Anal. 2007, 15, 99-108.

41. Ministry of the Interior, R.O.C. (Taiwan). Monthly Bulletin of Interior Statistics. Available online: https: //www.moi.gov.tw/files/site_stuff/321/1/month/month.html (accessed on 6 February 2018).

42. Centers for Disease Control and Prevention, U.S. Department of Health \& Human Services. International Classification of Diseases, Ninth Revision, Clinical Modification (ICD-9-CM). Available online: https: //www.cdc.gov/nchs/icd/icd9cm.htm (accessed on 29 June 2016).

43. Agrawal, R.; Srikant, R. Mining sequential patterns. In Proceedings of the Eleventh International Conference on Data Engineering, Taipei, Taiwan, 6-10 March 1995; pp. 3-14.

44. Fournier-Viger, P.; Lin, J.C.W.; Gomariz, A.; Gueniche, T.; Soltani, A.; Deng, Z.H.; Lam, H.T. The SPMF Open-Source Data Mining Library Version 2. In Machine Learning and Knowledge Discovery in Databases, Proceedings of the European Conference, ECML PKdd 2016, Pt. III, Riva del Garda, Italy, 19-23 September 2016; Springer: New York, NY, USA, 2016; Volume 9853, pp. 36-40.

(C) 2019 by the authors. Licensee MDPI, Basel, Switzerland. This article is an open access article distributed under the terms and conditions of the Creative Commons Attribution (CC BY) license (http://creativecommons.org/licenses/by/4.0/). 